HID 40 (2013)

\title{
AUTENTICIDAD DE LA DONACIÓN DE FERNÁN GONZÁLEZ A SAN SEBASTIÁN DE SILOS (954)
}

\author{
REGARDING THE AUTHENTICITY OF FERNÁN GONZÁLEZ'S \\ DONATION TO SAN SEBASTIÁN DE SILOS IN 954
}

Miguel C. Vivancos

Abadía de Silos

mvivancos@yahoo.com

RESUMEN: Algunos estudiosos consideran falsos muchos de los documentos del conde Fernán González, entre ellos la carta dirigida al monasterio de San Sebastián de Silos, cuyo original no se ha conservado. En este artículo pretendemos demostrar la autenticidad de esta donación, sobre todo comparando sus fórmulas con las Formulae Visigothicae y las de otros documentos de la época que parecen seguir un formulario común, utilizado en los siglos X y XI en todo el reino de León.

Palabras ClaVe: Silos, León, Fernán González, Formulae Visigothicae, diplomática altomedieval.

ABSTRACT: Many documents associated with Count Fernán González are considered to be falsifications by a number of scholars, including the count's donation to the monastery of San Sebastián de Silos, whose original has not come down to us. The present article sets out the authenticity of the document, above all by comparing its formulas with the Formulae Visigothicae and those of other, contemporary documents which indicate they were composed using the same formulary, adopted during the tenth and eleventh centuries over the whole of the kingdom of León.

Keywords: Silos, León, Fernán González, Formulae Visigothicae, Early Medieval diplomatics. 
El primer documento del cartulario silense es una carta del conde Fernán González, que se dice fechada el sábado, 3 de junio del año 919. Hasta el último cuarto del siglo XX, como más adelante veremos, esta carta fue tenida por auténtica, pero desde entonces recayó sobre ella la sospecha de falsificación o, al menos, de interpolación. Intentar demostrar su entera genuinidad es el objetivo de estas páginas.

No se conoce copia más antigua del diploma que la incluida en el cartulario silense, un manuscrito escrito en la segunda mitad del siglo XIII que, sin embargo, no copia el documento del original, sino de una confirmación de Alfonso X, del 15 de octubre de $1255^{1}$. El original de esta confirmación no se nos ha conservado, pero el cartulario la transcribe con exactitud. Por ella sabemos que la carta de Fernán González fue copiada de "un priuilegio sin seello e con signos", y que era "uieio"2.

Del 16 de junio de 1315 es una traducción del texto latino, que se dice hecha sobre una copia sacada a su vez del documento tenido por original:

Mostraron un traslado que dizía que era de priuilleio que an el abbat e el conuento del dicho monesterio, el qual traslado es escripto e signado por mano de Iohan Pérez, escriuano público de Burgos. Et los dichos monges dixieron que el priuilleio primero era escripto en latín e ellos que auien mester de se aprouechar del traslado tornado en romançe ante los tutores de nuestro sennor el rey e ante sus alcalles. Et pidieron a los alcalles sobredichos que mandasen a mi Pero Martínez, escriuano público de Burgos que estaua presente, que trasladase en romançe el tenor del priuilleio que estaua escripto en latín en el traslado que y mostraron, que es escripto por mano del dicho Iohan Pérez, e lo tornase en pública forma dándome para ello autoridat e poder ${ }^{3}$.

Tenemos, pues, noticia de una copia en latín, sacada sobre el original por el escribano Juan Pérez, que sirvió de base a una traducción castellana, que conservamos inserta en las actas de un proceso que enfrentó al monasterio con el concejo de Silos por cuestiones de señorío y jurisdicción ${ }^{4}$. La copia latina del escribano Juan Pérez no se ha conservado.

Perdido el documento original y otras copias, nos quedan del privilegio de Fernán González los siguientes testimonios manuscritos:

1. Sobre este cartulario, vid. J.C. DE LERA MAÍLLO. "Noticia descriptiva del cartulario gótico del Monasterio de Silos", Silos. Un milenio. Actas del Congreso Internacional sobre la Abadía de Santo Domingo de Silos (II. Historia), Silos, 2003 (Stvdia Silensia XXVI), pp. 521-540; M.C. VIVANCOS. Catálogo del archivo del monasterio de Santo Domingo de Silos, Silos, 2006 (Stvdia Silensia XXIX), p. 207.

2. M.C. VIVANCOS. Documentación del monasterio de Santo Domingo de Silos (1255-1300), Silos, 1995 (Stvdia Silensia XVIII), p. 81 (doc. 203).

3. J.A. GARCÍA LUJÁN. Códice Diplomático procesal del Monasterio de Santo Domingo de Silos (1346): estudio codicológico, paleográfico, diplomático y edición, Córdoba, 1996, p. 66.

4. La traducción castellana íntegra en ibidem, pp. 65-68. Las actas del proceso se hallan en el archivo de los Duques de Frías, Velasco 1837, hoy en el Archivo Histórico Nacional, Sección Nobleza. 
B. Archivo del monasterio de Silos (=AMS), ms. 17, fols. 1-2v; cartulario del siglo XIII med., inserto en confirmación de Alfonso X, Valladolid, 15 de octubre de 1255 .

C. Archivo de los duques de Frías (Archivo Histórico Nacional, Sección Nobleza), Velasco 1837 , fols. 3v-5v; actas de un proceso cuya sentencia final está fechada en Madrid, el 30 de diciembre de 1345, en traducción castellana hecha en 1315 .

D. AMS, ms. 21, fols. 181r-v; G. Ruiz de Montiano, Historia milagrosa de Santo Domingo de Silos, del año 1615.

E. AMS, B-XXXVI, 13, fols. 403-406; ejecutoria de un pleito de 1770, que reproduce la confirmación de Alfonso X, fechada en Valladolid el 15 de octubre de 1255 .

F. Biblioteca Nacional de Madrid, ms. 3546, fols. 113-114v, en copia de 1798, que reproduce la confirmación de Alfonso X, fechada en Valladolid el 15 de octubre de 1255 .

Interesantes son también algunas ediciones o citas de los autores antiguos. El primero en citar este diploma es Esteban de Garibay, en 1571. No transcribe el documento, pero lo cita en dos ocasiones; parece haber visto la confirmación de Alfonso X, pero ofrece un cambio importante en la data del privilegio:

Consta lo mesmo por un privilegio dado por el conde Don Fernán Gonçález al monasterio de Santo Domingo de Silos, de la Orden de San Benito, hecho en tres de las kalendas de junio de la era de nuevecientos y cinquenta y siete, que es a treynta de mayo del año del nacimiento de nuevecientos y diez y nueve, donde el conde Don Fernán Gonçález a este monesterio otorgando donación de las tierras y términos de su comarca; dize hazer la donación reynando en León el rey Don Ordoño, y siendo conde de Castilla el mesmo conde Don Fernán Gonçález, y la condessa Doña Sancha su muger, y porque deste privilegio hablaré algo más copioso en la historia del mesmo conde, baste esto para evidencia de nuestro propósito 5 .

Entre los antiguos privilegios que en el monesterio de Santo Domingo de Silos, de la Orden de San Benito, se hallan, es uno, dado por el conde Don Fernán Gonçález a este monesterio en tres de las kalendas de junio de la era de novecientos y cincuenta y siete, que es a treynta de mayo del año del nacimiento de nuestro Señor Iesuchristo de novecientos y diez y nueve. El conde Don Fernán Gonçález haze por este privilegio donación a este monesterio de la tierra, términos, ríos, molinos, montes y pastos donde el monesterio está fundado, cuyo comienço, según se colige desta escritura, es más antiguo que destos tiempos. Haze esta donación llamando al monesterio San Sebastián de Silos, cuyo assiento es a tres leguas de la villa de Covarruvias en una sierra, camino de San Estevan de Gormaz, en el valle que en este tiempo se dezía Tablatello y después, con el progreso del tiempo, viniendo a ser abad desta casa el glorioso Santo Domingo, vino muchos años después de su santo fallecimiento, que adelante en su lugar se señalará, a perder el nombre y advocación primera de San Sebastián de Silos y a llamarse Santo Domingo de Silos, pero

5. E. DE GARIBAY. Compendio historial de las chrónicas y universal historia de todos los reynos de España, vol. I, Barcelona, 1628, p. 380. 
en el altar mayor permanece hasta nuestros dias la advocación de San Sebastián, como yo mesmo lo he sido en notar. Agora ay en el lugar donde el monesterio está una villa, la qual quándo se pobló mostrará nuestra historia en su tiempo y lugar; y después el rey Don Alonso el Sabio confirmó este priuilegio dado por el conde Don Fernán González, el qual refiere hazer esta donación reynando en León el rey Don Ordoño y siendo conde en Castilla el mesmo conde Fernán Gonçález ${ }^{6}$.

El siguiente historiador en tener en cuenta nuestro documento fue fray Antonio de Yepes, quien ofrece su primera edición ${ }^{7}$. Este benemérito autor opina que "aunque el privilegio no es muy elegante, sino de latín grossero y bárbaro de aquel tiempo, con todo esso es muy digno de ser leydo y entero le pondré en la Apéndice". Y ahí lo presenta de la siguiente forma:

Escritura XXXVIII. Es el traslado de una carta de donación que hizieron Fernán Gonçález y su muger Doña Sancha, en favor del monasterio de S. Sebastián de Silos; sirve para la historia desta abadia, que aora se llama S. Domingo, de la qual se trata el año 919. Dexé la escritura con los malos latines de aquel tiempo, para que se conozca que en el siglo que vivió el conde Fernán Gonçález más se tratava en España de manejar las armas que de hablar con elegancia 9 .

Dom Marius Férotin dijo en su momento que la transcripción de Yepes contenía "des nombreuses incorrections" ", lo que no es del todo cierto, ya que ni son tantos los errores y diferencias ni de mucha monta, salvo los referentes a la data y a la suscripción condal, como en su lugar veremos.

De entre los autores posteriores a Yepes, tiene noticia de esta carta el monje de Silos, Fray Ambrosio Gómez, pero se limita a seguir a su ilustre hermano de hábito ${ }^{11}$. Mayor interés tiene lo dicho por el jesuita Padre José de Moret:

Y cinco años antes, en la era de 957, firma Doña Sancha como muger del conde la donación que este hiço a S. Sebastián de Silos y su abad D. Placencio de la villa de Silos con todos sus términos y jurisdición, como consta del instrumento de aquella

6. Ibidem, pp. 436-437. A Garibay lo citará años después J. DE FERRERAS. Synopsis histórica chronológica de España. Parte décima sexta, Madrid, 1775, pp. 110-111.

7. A. DE YEPES. Corónica general de la Orden de San Benito, vol. IV, Valladolid, 1613, fols. 457v-458. La transcripción de Yepes fue publicada de nuevo por el cardenal Sáenz de Aguirre, quien indica expresamente de dónde la toma, sin variantes (J. SÁENZ DE AGUIRRE. Collectio maxima conciliorum omnium Hispaniae et novi orbis, vol. III, Roma, 1694, pp. 175-176). Del cardenal se sirven los benedictinos de San Mauro, continuadores del famoso diccionario del Señor Du Cange, al citar nuestro documento en las voces Deliminare y Fosca (C. DU FRESNE. Glossarium mediae et infimae latinitatis, vol. III, Niort, 1884, pp. 52; 577). Estas entradas no pueden deberse al Señor Du Cange, como afirma Férotin para Fosca (M. FÉROTIN. Recueil des chartes de l'abbaye de Silos, París, 1897, p. 2, n. 1), pues la primera edición de su glosario es de 1678 y él muere en 1688, antes de la publicación de la obra del cardenal.

8. A. DE YEPES. Corónica general..., fol. 368v.

9. Ibidem, fol. $457 \mathrm{v}$.

10. M. FÉROTIN. Recueil des chartes..., p. 4.

11. A. GÓMEZ. El Moysen segundo, nuevo redentor de España, N. P. Santo Domingo Manso, monge benito (aclamado hasta ahora Santo Domingo de Silos), Madrid, 1653, pp. 106-107. 
casa que se trae en la recopilación de ellos, que llaman Historia manuscripta [en nota: Histor. manuscrpt. monasterii Silensis, fol. 182: Factum est \& confirmatum testamentum scriptionis vel confirmacionis, notum die era 957 \& c. Et princeps terrce huius rex Ordonio in Legione, comite vero Guindisaluo in Castalle (sic). Ego vero Fredinandus Gundisaluiz \& uxor mea Sancia quod fecimus roborauimus, \& c. $]^{12}$.

Del archivo de Santo Domingo de Silos ya alegamos arriba la escritura en que el conde Fernán Gonçález con su muger Doña Sancha, aunque sin título de condes todavía, daban al abad Placencio la villa de Silos, y remata se hiço en la era 957 (año de Christo 919), reynando nuestro Señor Iesuchristo en los cielos y príncipe desta tierra el rey D. Ordoño en León, y conde D. Gonçalo en Castilla. Yo, Fernán Gonçález, y mi muger Doña Sancha roboramos nuestra donación y hicimos el signo de la cruz. [en nota: Archivo de Silos in Hist. ms., fol. 182: Era D.CCCCLVII, regnante Domino nostro Iesu Christo in coelis \& princeps terre huius rex Ordonio in Legione, comite vero Gundisaluo in Castella. Ego vero Fredinandus Gundisaluiz \& vxor mea Sancia quod fecimus roborauimus \& signum crucis fecimus $]^{13}$.

El Padre Moret dice expresamente en las dos ocasiones haber tomado estos datos de una historia manuscrita del monasterio de Silos. No puede referirse sino a la Historia milagrosa de Santo Domingo de Silos, abad de la Orden de San Benito, que contiene las marauillas deste Santo en vida y muerte, y los antiguos sucesos de su real monasterio y de sus prioratos y filiaciones, obra de Fray Gaspar Ruiz de Montiano que, preparada para la imprenta, quedó sin embargo inédita ${ }^{14}$. Ya la hemos citado, porque en su apéndice documental copia el privilegio de Fernán González, y es de aquí de donde lo toma Moret sin lugar a dudas, aunque él diga que lo toma del fol. 182 cuando, en realidad, está al fol. 181.

Fray Domingo la Ripa depende también de Yepes $^{15}$, al igual que el monje de Silos, Fray Juan de Castro, que nada importante añade en lo que dice en su historia de Santo Domingo de Silos, publicada en $1688^{16}$. La carta de Fernán González también es citada por Don Luis de Salazar y Castro, pero la conoce a través de Moret y, por tanto, en la versión de Gaspar Ruiz de Montiano ${ }^{17}$.

12. J. DE MORET. Investigaciones históricas de las antigüedades del reyno de Navarra, Pamplona, 1665 , p. 346.

13. Ibidem, pp. 467-468.

14. Vid. M.C. VIVANCOS. Documentación del monasterio de Santo Domingo de Silos (9541254), Burgos, 1988 (Fuentes medievales castellano-leonesas 50), pp. LIV-LV; M.C. VIVANCOS. Catálogo del archivo..., p. 208.

15. D. LA RIPA. Defensa histórica por la antigüedad del reino de Sobrarbe, Zaragoza, 1675, pp. $367 ; 405$.

16. J. DE CASTRO. El glorioso thaumaturgo español, redemptor de cautivos, Santo Domingo de Sylos, Madrid, 1688, pp. 271-273.

17. L. SALAZAR Y CASTRO. Historia genealógica de la casa de Lara, vol. I, Madrid, 1696, pp. $39-40 ; 43$. 
Fray Francisco de Berganza conoce el privilegio por su hermano de religión, el Padre Yepes, pues como él modifica la suscripción condal ${ }^{18}$. También tenía por fuerza que ser conocido por el Padre Enrique Flórez; lo cita por vez primera al hablar de los condes castellanos y sus escrituras, pero lo hace remitiendo a Moret ${ }^{19}$. Vuelve a citarlo y hacer uso abundante de él al hablar de los orígenes del monasterio de $\operatorname{Silos}^{20}$, pero sin decir de dónde lo toma. Cabe presumir que de Yepes, a quien cita en estas páginas, aunque en honor a la verdad justo es decir que también Flórez visitó Silos y pudo ver por sí mismo alguna copia manuscrita ${ }^{21}$. En cualquier caso, las pocas líneas que ofrece no presentan divergencia alguna de interés.

La primera edición que podemos calificar de moderna es la de Dom Marius Férotin en 1897, basándose en el cartulario y teniendo a la vista la edición de Ye$\operatorname{pes}^{22}$. A ellas le siguen cronológicamente la nuestra ${ }^{23}$, y la de Manuel Zabalza ${ }^{24}$.

Antes de analizar la veracidad o falsedad de este diploma convendrá fijarse en las diferencias que nos ofrecen las distintas copias que de él conocemos. Puede decirse que hay una identidad básica; salvo pequeñas variantes, el texto ofrecido es siempre el mismo. Pero hay una importante divergencia en la data y en la suscripción condal. Por un lado, tenemos los testimonios coincidentes de B (de quien dependen $\mathrm{E}$ y F) y C:

B

Factum et confirmatum hunc testamentum scriptionis vel confirmationis, notum die sabbato, III nonas iunias, era DCCCCLVII, regnante Domino nostro Ihesu Christo in celis et princeps terre huius rex Ordonio in Legione, comite vero Fredenando Gundisalvet in Castella.
$\mathrm{C}$

Fecho e confirmado e escripto es este nuestro testamento de confirmaçión en día connosçido, conuiene a saber, día de sábado tres días del mes de junio era de nueueçientos e çinquenta e siete annos, regnante el nuestro sennor Ihesuchristo en los çielos. Et prinçep desta tierra don Ordonno rey de León. Et conde en Castiella don Ferrant Gonçález.

18. "El privilegio de Santo Domingo de Silos que concedió el conde Fernán Gonçález solo dize que era conde de Castilla Gonçalo, sin explicar el nombre patronímico" (F. DE BERGANZA. Antigüedades de España, vol. I, Madrid, 1719, p. 191).

19. E. FLÓREZ. España sagrada, vol. XXVI, Madrid, 1771, p. 67.

20. E. FLÓREZ. España sagrada, vol. XXVII, Madrid, 1772, cols. 391-401.

21. Consta que visitó Silos en 1769 (ibidem, col. 100).

22. M. FÉROTIN. Recueil des chartes..., p. 1-4 (doc. 1). Análisis en M. FÉROTIN. Histoire de l'abbaye de Silos, París, 1897, pp. 8-11.

23. M.C. VIVANCOS. Documentación del monasterio de Santo Domingo de Silos (954-1254)..., pp. 3-5 (doc. 1$)$.

24. M. ZABALZA DUQUE. "Escrituras de fundación de los monasterios de Arlanza y Silos. Problemas sobre su autenticidad”, Boletín de la Institución Fernán González, LXXIV (1995), pp. 333-361, praes. pp. 340-342 (doc. 3); M. ZABALZA DUQUE. Colección diplomática de los condes de Castilla: edición y comentario de los documentos de los condes Fernán González, García Fernández, Sancho García y García Sánchez, Valladolid, 1998, pp. 271-273 (doc. 29). 
Por contra, D (Ruiz de Montiano) y Yepes:

\section{D}

Factum et confirmatum hunc testamentum scriptionis vel confirmationis, notum die era 957, regnante Domino nostro Ihesu Christo in cœlis et princeps terræ huius rex Ordonio in Legione, comite vero Gundisaluo in Castella.
Yepes

Factum \& confirmatum hunc testamentum scriptionis vel confirmationis, notum die era 957, regnante Domino nostro Ihesu Christo in cœlis \& princeps terræ huius rex Ordonio in Legione, comite vero Gundisaluo in Castella.

Y, finalmente, tenemos el testimonio independiente de Esteban de Garibay, arriba transcrito, que fechaba el diploma "en tres de las kalendas de junio de la era de nuevecientos y cinquenta y siete". Ya Férotin advirtió esta variante, pero no supo explicarla ${ }^{25}$. Es un testimonio único, frente a B y C, que fechan el documento en un sábado, 3 de junio, y frente a D y Yepes, que solo ofrecen la era. En realidad, solo hay diferencia en una sola palabra: donde B lee nonas, Garibay interpreta kalendas. En principio no parece fácil confundir nns o non con klds, pero en un documento antiguo y quizás deteriorado todo es posible. Cabe también que sea corrección propia de Garibay, consciente de que el 3 de junio del año 919 no cayó en sábado, pero es que tampoco lo fue el 30 de mayo de ese año, sino domingo. Aunque litúrgicamente hablando, si el documento fue expedido en la tarde del sábado, 29 de mayo, ya se estaría en el día 30. Pero esta interpretación complica aún más las cosas. Porque, sea de ello lo que sea, todos los autores modernos están concordes en ver un error importante en el año, y no tanto en el día de la semana.

Yepes y Ruiz de Montiano coinciden al no ofrecer indicación de día de la semana ni de mes; tan solo dan el año y además modifican la suscripción condal. Estos dos autores se copian el uno al otro y ofrecen la misma idéntica versión del privilegio, pues los dos coinciden siempre frente a $\mathrm{B}^{26}$. Es muy posible que el autor de la transcripción sea el monje silense Gaspar Ruiz de Montiano, quien la comunicaría a Yepes, su hermano de profesión, a quien ofreció también por escrito otras noticias históricas del monasterio silense ${ }^{27}$. No parece que las omisiones en la data se deban a un error, sino que parecen intencionadas. Al menos así lo pensa-

25. "Nous ignorons où il a pris cette variante" (M. FÉROTIN. Recueil des chartes..., p. 3, n. 4). Pero se equivoca al decir que Garibay fecha la carta el 29 de mayo, cuando lo hace el 30.

26. Por ejemplo (ponemos en primer lugar el texto de B y tras la barra inclinada el de D y Yepes): post Deum/ post Dominum; gignitur/ gignuntur; nullius quidem/ nulliusque; fosce/ fosca; ut eum/ ut cum; futuris/ fratres; conversatione/ consideratione; fuerint/ fecerint; quisquis/ quod si quis; pargiet/ purget.

27. Yepes trata del monasterio de Silos en el tomo IV de su Corónica (A. DE YEPES. Corónica general..., fols. 368v-386v). La descripción que ofrece del relicario del monasterio es obra del Padre Gaspar: "Encargóse de embiarme la traça y el número de las reliquias Fray Gaspar Ruyz, hijo de Santo Domingo de Silos, predicador que reside en aquel convento, persona conocida en España por el libro que publicó de Séneca" (ibidem, fol. 379v). Además Fray Antonio de Yepes copia en su apéndice otra escritura del monasterio de Silos, un privilegio de Alfonso VII, que también el Padre Ruiz de Montiano trae en su Apendix de las escrituras que se citan en este libro, a continuación del privilegio de Fernán González (ibidem, fols. 458r-v; AMS, ms. 21, fols. 181v-182). 
ba Dom Férotin ${ }^{28}$. De esta forma se obviaba la dificultad que suponía admitir que el 3 de junio del año 919 fue sábado, como dice el documento, cuando en realidad fue jueves. Pero esta explicación no valdría para el cambio de la suscripción condal, porque para Yepes y los autores que le siguen no suponía ningún problema aceptar que Fernán González fuera conde en Castilla en el año $919^{29}$.

Parece, pues, que hemos de quedarnos con la fecha que presentan las copias más antiguas, sin atender a las correcciones de Ruiz de Montiano y sus seguidores por un lado y de Garibay por el otro. El problema estriba en que, tal como nos ha sido transmitida, esta data es a todas luces incorrecta:

Factum et confirmatum hunc testamentum scriptionis vel confirmationis, notum die sabbato, III nonas iunias, era DCCCCLVII.

El tercer día antes de las nonas del mes de junio de la era 957, esto es, el 3 de junio del año del nacimiento de Cristo 919, no fue sábado, sino jueves. Dom Férotin, para quien el error está solo en el día de la semana, no en el año, encontró una explicación sencilla: en lugar de leer III non. iun., habría que leer in non. iun., lo que nos da el 5 de junio, que, efectivamente, cayó en sábado aquel año. Pero es incorrecto decir in nonas iunias, pues sobra en este caso la preposición; además el problema estriba en que es imposible admitir que el año 919 Fernán González ejerciera como conde de Castilla y estuviera ya casado con Doña Sancha. Dom Luciano Serrano se acoge al testimonio de las copias que dependen de Ruiz de Montiano y soluciona la primera objeción haciendo firmar al conde Gonzalo, pero nada dice de la segunda ${ }^{30}$. Fue otro insigne benedictino silense, el Padre Justo Pérez de Urbel, quien ofreció la explicación más razonable. Si existía un fallo, este estaba solo en el año, a todas luces erróneo. Era necesario buscar uno en que no extrañara la mención de un monarca llamado Ordoño en León con el ejercicio del poder condal en Castilla por Fernán González, casado con Doña Sancha, y en presencia de unos testigos que Fray Justo localizaba a mediados del siglo X. En los años de los reinados de Ordoño III y Ordoño IV solo el de 954 cayó en sábado el 3 de junio ${ }^{31}$. Situado en el año 954, el documento no ofrecía ya ninguna dificultad y podía ser utilizado con total tranquilidad.

Y así lo hicieron muchos historiadores a partir de ese momento, aunque no sin ciertas reticencias por parte de otros. Entre estos últimos hay que contar a Antonio Linage quien, en 1973, en su magna obra sobre el monacato benedictino en la península ibérica, calificó de interpoladas muchas menciones a la Regula Benedicti en los documentos del siglo X del área castellano-leonesa. Falsas serían las de los monasterios de Sahagún en 905, Arlanza en 912, Eslonza en 913, Albelda en 924,

28. "Yepes avait sans doute prévu la difficulté; il ne reproduit en effet aucune indication de jour ni de mois" (M. FÉROTIN. Recueil des chartes..., p. 3, n. 4).

29. Férotin advierte el error en Berganza y Moret, pero no lo explica (ibidem, p. 4, n. 1).

30. L. SERRANO. El obispado de Burgos y Castilla primitiva desde el siglo V al XIII, vol. I, Madrid, 1935, p. 139, n. 2.

31. J. PÉREZ DE URBEL. Historia del condado de Castilla, vol. I, Madrid, 1945, pp. 362-364. 
San Juan de Tabladillo en 924, Silos en 954, etc., pero, por contra, serían auténticas, entre otras, las de los monasterios de Abellar en 905, Albelda en 955 o San Millán en $971^{32}$. Sobre el documento silense se cierne la sospecha de falsedad o, al menos, la de manipulación ${ }^{33}$.

En 1995 Manuel Zabalza Duque publicó, por lo que hace a Silos y Arlanza, un adelanto de su tesis doctoral, publicada tres años después ${ }^{34}$. Por sus fórmulas diplomáticas, por la mención de la Regula Benedicti y por el error en la data, la carta silense es tachada de falsa en su totalidad.

A favor de la autenticidad del diploma, sin conocer el artículo de Zabalza de 1995, rompe una lanza Ernesto Pastor Díaz de Garayo ${ }^{35}$. Arreglada la cuestión de la fecha, ni el tenor diplomático general, ni la delimitación del coto y término del monasterio, ni la mención benedictina pueden alegarse a favor de la falsedad del diploma.

A partir de aquí, por lo general, los historiadores se han puesto del lado de Zabalza $^{36}$. Nosotros manifestamos en varias ocasiones nuestras dudas al respecto, admitiendo que el privilegio contenía algún fondo de verdad, pero sin profundizar más en la cuestión ${ }^{37}$. Es lo que nos proponemos hacer a continuación, animados por la reciente aparición de una donación, presumiblemente original, del conde Fernán González al monasterio de Arlanza ${ }^{38}$.

32. Un listado completo en A. LINAGE CONDE. Los orígenes del monacato benedictino en la península ibérica, 3 vols., León, 1973, vol. III, pp. 513-532.

33. Ibidem, vol. II, pp. 617-619.

34. M. ZABALZA DUQUE. "Escrituras de fundación...”. Y en la tesis, M. ZABALZA DUQUE. Colección diplomática de los condes de Castilla..., pp. 113-130.

35. E. PASTOR DÍAZ DE GARAYO. "Los testimonios escritos del sector meridional de Castilla (siglos X-XI). Ensayo de crítica documental”, Historia. Instituciones. Documentos, 24 (1997), pp. 355-380.

36. Por ejemplo, J.A. GARCÍA DE CORTÁZAR. "Monasterios románicos de Castilla y conservación de la memoria histórica", Monasterios románicos y producción artística, Aguilar de Campoo, 2003, pp. 9-33, praes. p. 27; G. MARTÍNEZ DÍEZ. El condado de Castilla (711-1038). La historia frente a la leyenda, 2 vols., Valladolid, 2005, vol. I, pp. 292-293; vol. II, p. 758; J.L. SENRA. "Mutatis mutandis: creaciones apócrifas en el monasterio de San Pedro de Arlanza (Burgos)”, Cahiers de linguistique hispanique médiévale, 29 (2006), pp. 23-43, praes. p. 36. En cambio, admite su validez I. BANGO TORVISO. "Reformas monásticas y litúrgicas en relación con los edificios románicos de Santo Domingo de Silos”, J.A. GARCÍA DE CORTÁZAR, R. TEJA CASUSO. (Coord.) Los grandes monasterios benedictinos hispanos de época románica (1050-1200), Aguilar de Campoo, 2007, pp. 141-165, praes. pp. 145-146.

37. M.C. VIVANCOS. "El Monasterio de Silos y su scriptorium; Catálogo. El scriptorium silense y los orígenes de la lengua castellana”, J.C. ELORZA. (coord.) El scriptorium silense y los origenes de la lengua castellana, Valladolid, 1995, pp. X-XL; 1-33, praes. pp. XII-XIII; M.C. VIVANCOS. "Circulación de manuscritos en la Edad Media: el caso de San Millán y Silos", M. BIELAWSKI, D. HOMBERGEN. (coords.) Il monachesimo tra eredità e aperture, Roma, 2004 (Studia Anselmiana 140), pp. 785-802, praes. p. 786; M.C. VIVANCOS. "Santo Domingo de Silos, Monasterio de", Gran Enciclopedia de España, vol. XX, Barcelona, 2004, pp. 9600-9602.

38. J. ESCALONA, I. VELÁZQUEZ, P. JUÁREZ. "Identification of the sole extant original charter issued by Fernán González, Count of Castile (932-970)", Journal of Medieval Iberian Studies, 4/2 (2012), pp. 259-288. Personalmente creemos con estos autores que el documento en cuestión es original, pero no nos sirve para compararlo con el silense, porque ambos utilizan formularios completamente diferentes. 
Es cierto que, en época moderna, nadie ha visto el documento original de Fernán González a San Sebastián de $\operatorname{Silos}^{39}$, pero esto no significa que no existiera. La única mención que pudiera referirse a este original es la de la confirmación de Alfonso X, del 15 de octubre de 1255, donde se dice que le fue presentado "un priuilegio sin seello e con signos del conde Ferrand Gonçaluez que me mostro don Rodrigo, abbat de Sancto Domingo de Silos", y que además era "uieio"40. Escuálida descripción, es verdad, que lo mismo puede referirse al original que a una copia de los siglos XI y XII, pero que a priori no excluye que, efectivamente, se tratara del original, el mismo que pudo ser copiado de nuevo en 1315, como hemos dicho más arriba. Se impone, pues, un estudio interno del documento para probar su veracidad o falsedad.

A primera vista, el único fallo manifiesto es el de la data; es imposible que el documento haya sido expedido el año 919, porque para entonces ni Fernán González era conde de Castilla ni estaba casado con Doña Sancha. La solución ofrecida por Fray Justo Pérez de Urbel nos sigue pareciendo acertada; los errores en las datas son frecuentísimos en las copias de documentos antiguos. No es tan difícil convertir una era d ccce $L x^{L}$ IIA en era d ccce LUIIA, habida cuenta de la dificultad que entraña interpretar bien el signo visigótico para cuarenta $\left(\mathrm{X}^{\mathrm{L}}\right)$. Toda la cuestión radica en convertir una $x$ aspada con valor de cuarenta en una $u$ con valor de cinco. En cualquier caso, siempre es conveniente no actuar a la ligera y tener en cuenta el acertado juicio del profesor Santiago Domínguez ${ }^{41}$; en nuestro caso, si la data correcta fuera la del año de Cristo 919, entonces habría que tachar a todo el documento de falso, por muy bien redactado que estuviera. Pero los errores de datación ocurren y la solución de Fray Justo se antoja muy razonable.

Analicemos ahora la estructura diplomática del diploma. Es evidente el uso de formularios jurídicos en esta época; por eso no ha de extrañar que párrafos enteros de nuestro documento se hayan copiado de modelos visigóticos ${ }^{42}$. Así sucede con la invocación trinitaria y la dirección (desde In nomine hasta requiescunt), toma-

39. M. ZABALZA DUQUE. Colección diplomática de los condes de Castilla..., pp. 119-120.

40. M.C. VIVANCOS. Documentación del monasterio de Santo Domingo de Silos (12551300)..., p. 81 (doc. 203). Estos signos podrían ser similares a los que aparecen en el documento recientemente recuperado en la British Library, de Londres, de la donación de Cárdaba, o los reproducidos en un grabado de 1773, de la donación de Fernán González a Arlanza (ejemplares en el archivo del monasterio de Silos, grab. 26).

41. "De todos es sabido que la Cronología técnica, disciplina que se enmarca dentro de la Diplomática y que estudia los problemas en torno a la fecha de los documentos, especialmente los altomedievales, no recomienda plantear soluciones a la ligera. Es muy fácil decir que a un scriptor medieval se le olvidó añadir una o dos "C", o que un transcriptor de época moderna de textos medievales no supo interpretar una " $X$ " aspada. Si no tenemos garantía de lo que ocurrió, es más prudente avisar de los problemas, y no dar como definitivas soluciones que pueden no serlo, o que no lo serían si tuviéramos más datos en la mano" (S. DOMÍNGUEZ SÁNCHEZ. "En torno a las puntualizaciones sobre la datación de documentos medievales de la catedral de Astorga", Estudios Humanísticos. Historia, 4 (2005), pp. 297-302, praes. p. 299).

42. M. ZABALZA DUQUE. Colección diplomática de los condes de Castilla..., p. 91; E. PASTOR DÍAZ DE GARAYO. "Los testimonios escritos...”, p. 359. A partir de aquí iremos citando continuamente a estos dos autores, lo que nos excusa de remitir continuamente a sus respectivos trabajos. 
das de la Formula Visigothica VIII ${ }^{43}$. De esta misma fórmula depende parte del preámbulo y el inicio de la parte dispositiva (desde piacolorum hasta videntur). El uso del término suburbio para designar el lugar en el que está fundada la basílica objeto de la donación está suficientemente atestiguado por esta época en la documentación medieval, designando "un faubourg aggloméré à un château, à un monastère ou à une ville modeste fortifié" 44 .

Dentro de la dirección aparece la mención, entre los patronos del monasterio, a San Millán de la Cogolla, lo que para Zabalza resulta altamente sospechoso, porque encuentra más lógico este recuerdo en época de Santo Domingo de Silos (1041-1073), abad silense que procedía del cenobio riojano. Siendo esto verdad, no lo es menos que el culto a San Millán ya se había extendido allende la Rioja al menos desde el siglo IX ${ }^{45}$, y que un documento silense del año 979, cuya autenticidad nadie ha puesto en duda, vuelve a citar a San Millán entre los titulares de la basílica silense ${ }^{46}$.

43. "Alia. Dominis sanctis atque gloriosissimis et post Deum nobis fortissimis patronis uenerandis illis martiribus, quorum reliquię in basilica qui in loco illo fundata est requiescunt, ill. et ill. peccatores serui uestri. Piaculorum nostrorum cupientes expiare flagitia et peccatorum nostrorum oneris prægrauationem orationum uestrarum desiderantes adiutorio subleuari, parba pro magnis offerimus munuscula. Nullius quidem in hoc seculo hominum uos indigere censum scimus, quia iam per sanctificationem Dominus noster suo in regno propitio dictatos munere cumulauit. Ergo pro luminaria ecclesiæ uestræ atque stipendia pauperum uel qui in aula beatitudinis uestræ quotidianis diebus deseruire uidentur, donamus gloriæ uestræ in territorio ill. loco ill. ad integrum, sicuti a nobis nunc usque noscitur fuisse possessum, cum mancipiis nominibus designatis, id est, ill. et ill. cum uxore et filiis, similiter ædificiis, uineis, siluis, pratis, pascuis, paludibus, aquis aquarumque ductibus uel omni iure loci ipsius, omnia, ut diximus, gloriæ uestræ deseruientes pro luminaria ecclesiæ uestræ atque stipendia pauperum uel substancia sua absque episcopali inpedimento post iure gloriæ uestræ perpetuo tempore debeant uindicare, ut nec uendere nec donare nec modicum aliquis alienare præsummat, sed integrum, ut nostræ oblationis continet forma, perpetuo tempore cultores ecclesiæ uestræ post uestro uindicent iure. Quod si quispiam ex cultores basilicæ uestræ ex hoc, quod prona uoluntate et sincera deuotione obtulimus, per tepiditate naufragauerit aut per quolibet contractu uel modicum a ius sanctæ ecclesię uestræ alienare presumpserit, nullatenus ualeat, sed ubi hoc succesor eius primum esse repererit, ut legis est exinde sentencia, nullius expectato iudicio sine alicuius controuersia in iure sancto uestro faciat reuocare. Quod etiam iuratione" (K. ZEUMER. Formulae merowingici et karolini aevi. Accedvnt ordines ivdiciorvm Dei, Hannover, 1886 (MGH, Legvm Sectio V, Formvlæ), p. 579; J. GIL, Miscellanea Wisigothica, Sevilla, 1972, pp. 80-81). Nótese que la fórmula va dirigida a varios santos, en plural, y las dificultades que tiene el autor de la donación de Modúbar, que reproducimos más abajo, en el cuadro comparativo, para ponerla en singular.

44. J.F. NIERMEYER, C. VAN DE KIEFT. Mediae Latinitatis Lexicon Minus, vol. II, Leiden, 2002, pp. 1306-1307, s. v. suburbium; M. SECO. (coord.) Léxico hispánico primitivo (siglos VIII al XII). Versión primera del Glosario del primitivo léxico iberrománico, Madrid, 2008, pp. 606-607, s. v. suburbio, con suficientes ejemplos del área castellano-leonesa.

45. C. GARCÍA RODRÍGUEZ. El culto de los santos en la España romana y visigoda, Madrid, 1966, p. 353. El año 922 se cita una iglesia dedicada a San Millán en las cercanías de Sahagún: J.M. MÍNGUEZ FERNÁNDEZ. Colección diplomática del monasterio de Sahagún (siglos IX y X), León, 1976, pp. 60-61 (doc. 29).

46. M.C. VIVANCOS. Documentación del monasterio de Santo Domingo de Silos (954-1254)..., p. 6 (doc. 2). 
La intitulación de Fernando y Sancha, nobisque indignis, no vuelve a aparecer en los diplomas fernandinos que Zabalza tiene por auténticos, pero no es raro el calificativo aplicado al donante en documentos del siglo $\mathrm{X}^{47}$.

Como ya hemos visto, parte del preámbulo depende de las Formulae Visigothicae, mientras que el comienzo Licet primordia, hasta provocat, es suficientemente conocido en esta época y usado con frecuencia como uno de los llamados preámbulos éticos ${ }^{48}$.

La parte dispositiva se inspira, como afirma Zabalza, en el modelo de las Formulae, y por lo que hace al deslinde y a la extensión del coto monasterial nada resulta sospechoso, como sostiene Ernesto Pastor, buen conocedor del espacio geográfico del Arlanza al Duero. Es verdad que esta es la parte más susceptible de ser amañada, pero precisamente la reducida extensión del coto silense habla a su favor. Como ha puesto de manifiesto Pastor, este coto será mayor (bastante más, añadimos nosotros) en 1155, cuando sea confirmado por Alfonso VII, lo que parece garantizar la autenticidad del reducido término del siglo $\mathrm{X}^{49}$.

Estos límites son concedidos para siempre a los monjes que allí viven bajo la autoridad del abad Placencio y la guía de la Regla de San Benito. Como ya hemos dicho, Antonio Linage considera esta mención al código benedictino interpolada, pero Ernesto Pastor ha puesto de manifiesto la arbitrariedad con que este autor acepta o rechaza tales menciones a lo largo del siglo $\mathrm{X}$, sin aducir más pruebas que sus sospechas. Si hay menciones auténticas desde el año 905 para el área castellano-leonesa-riojana, habrá que demostrar fehacientemente la falsedad de otras pues, de lo contrario, habrá que darlas por válidas. No hay que olvidar que Silos contaba desde el año 945 con un manuscrito, obra de un copista llamado Juan, que contenía la Expositio in Regulam Sancti Benedicti, de Esmaragdo ${ }^{50}$, texto clave para entender el proceso de benedictinización del monacato hispano.

La parte conminatoria (desde nullusque hasta presumant) es, efectivamente, como dice Zabalza, un poco confusa, pero no carece de importantísimos paralelos, como a continuación veremos. En cambio, las cláusulas penales son breves y concisas, pues no se mencionan penas espirituales y tan solo una pena pecuniaria.

Esta mezcla de fórmulas visigóticas y del siglo $\mathrm{X}$, como ha puesto de relieve Pastor, no es exclusiva de nuestro documento. Varias cartas de dotación de mo-

47. Por ejemplo en Sahagún (J.M. MÍNGUEZ FERNÁNDEZ. Colección diplomática del monasterio de Sahagún..., pp. 137 (doc. 101); 198 (doc. 160); 200 (doc. 162); 407 (doc. 337); etc.). Y antes, en el año 865, en Valpuesta (J.M. RUIZ ASENCIO, I. RUIZ ALBI, M. HERRERO JIMÉNEZ. Los becerros gótico y galicano de Valpuesta, vol. I, [Burgos], 2010, p. 197 (doc. 4).

48. De nuevo en Sahagún en el año 922 (J.M. MÍNGUEZ FERNÁNDEZ. Colección diplomática del monasterio de Sahagún..., p. 61 (doc. 29). Sobre estos preámbulos, vid. L. LAFFÓN ÁLVAREZ, "Arenga hispana: una aproximación a los preámbulos documentales de la Edad Media”, Historia. Instituciones. Documentos, 16 (1989), pp. 133-232, praes. pp. 172-178.

49. E. PASTOR DÍAZ DE GARAYO. "Los testimonios escritos...", p. 364, n. 35; M.C. VIVANCOS, Documentación del monasterio de Santo Domingo de Silos (954-1254)..., p. 85 (doc. 60).

50. No ignoramos que el manuscrito está datado por el rey Ramiro II de León y el conde Fernán González de Castilla, pero no lleva indicación tópica. Sin embargo, todo apunta a que es obra del scriptorium silense (M.C. VIVANCOS. Glosas y notas marginales de los manuscritos visigóticos del monasterio de Santo Domingo de Silos, Silos, 1996 (Stvdia Silensia XIX), pp. 63-65). 
nasterios de este periodo son prácticamente idénticas, entre ellas las de Sahagún (año 905); San Pedro de Arlanza (912); y San Martín de Modúbar (944) ${ }^{51}$. Pero no son las únicas; habría que añadir la carta de dotación de Gonzalo Téllez a San Pedro de Arlanza, del 12 de enero del año 912; la de Gonzalo Télliz a San Jorge de Cerezo de Río Tirón, del 25 de octubre de 913; y la de Rodrigo Díaz a San Juan de Tabladillo, del 29 de diciembre de $924^{52}$. Siguen el mismo esquema, pero con mayores diferencias, las donaciones de la condesa Muniadona a Santa María de Lara, del 28 de enero de 929, y a San Millán de Belbimbre, del 1 de febrero de $929^{53}$. Sin embargo, aunque muchos de estos documentos nos parecen auténticos o a lo más interpolados, conviene establecer la comparación con algún documento fuera de toda duda. Aunque no sigan exactamente la misma estructura y formularios, son especialmente interesantes dos diplomas, porque se nos han conservado sus originales; el primero es el de la restauración del monasterio de San Román de Entrepeñas, llevada a cabo por Diego Muñoz y su mujer Tegridia el año $940^{54}$. El segundo es la donación del rey Vermudo II al monasterio de San Andrés de Pardomino, del 22 de octubre de 985, con fórmulas distintas, pero también con mención expresa de la Regla de San Benito ${ }^{55}$. Vamos a servirnos del primero y compararlo con el diploma silense y con la dotación de San Martín de Modúbar que parece ser igualmente auténtica ${ }^{56}$.

51. Las tres respectivamente en J.M. MÍNGUEZ FERNÁNDEZ. Colección diplomática del monasterio de Sahagún..., pp. 30-32 (doc. 8); M. ZABALZA DUQUE. Colección diplomática de los condes de Castilla..., pp. 113-115 (doc. 1); G. MARTÍNEZ DÍEZ. Colección documental del monasterio de San Pedro de Cardeña, Burgos, 1998, pp. 74-76 (doc. 43).

52. Respectivamente en L. SERRANO. Cartulario de San Pedro de Arlanza, Madrid, 1925, pp. 10-13 (doc. III); G. MARTÍNEZ DÍEZ. Colección documental del monasterio de San Pedro de Cardeña..., pp. 30-31 (doc. 6); L. SERRANO. Cartulario de San Pedro de Arlanza..., pp. 14-17 (doc. IV). La carta de Gonzalo Téllez a Arlanza, muy parecida, pero no idéntica a la silense, nos parece auténtica. No así la de Fernán González a Arlanza, de la misma fecha, que parece rehecha sobre la de Gonzalo, aunque es cuestión que no tratamos de dirimir aquí.

53. M. ZABALZA DUQUE. Colección diplomática de los condes de Castilla..., pp. 130-133 (docs. 2 y 3$)$.

54. J.M. RUIZ ASENCIO, I. RUIZ ALBI, M. HERRERO JIMÉNEZ. Colección documental del monasterio de San Román de Entrepeñas (940-1608), León, 2000, pp. 45-47 (doc. 1).

55. E. SÁEZ, C. SÁEZ. Colección documental del archivo de la catedral de León (775-1230). II (953-985), León, 1990, p. 317 (doc. 506).

56. Opinión que compartimos con E. PASTOR DÍAZ DE GARAYO. "Los testimonios escritos...”, pp. 363; 366; 369. Este diploma de Modúbar solo se nos ha transmitido en copia, en el llamado Becerro Gótico de Cardeña, fol. 14, escrito poco después de 1085 (G. MARTÍNEZ DÍEZ. Colección documental del monasterio de San Pedro de Cardeña..., pp. 10-12). 
ENTREPEÑAS (940)

${ }^{1}$ In nomine sancte et indiuidue Trinitatis.

${ }^{2}$ Ego, Didaco Monniz, una pariter cum coniuge mea Tegridia, inspirante diuina misericordia in cordibus nostris hac premeditantes futuram et deuitam condicione mortis humane, studuimus has baselicas restaurare, ampliare et ditare pro remedio animarum nostrarum, qualiter in iudicii diem Christus uenturus exercuerit nos pro hoc licet indigni $\mathrm{ab}$ auditu malo liueremini. In Dei nomine et in Christi amore et Sancte Eglesie perpetuali honore offerimus tibi, Lecinio, abba, hoc loco sancti Romani, uidelicet, et sancti Salbatoris, sancte Marie Uirginis et sancti Felicis Nolensis, sancti Ioannis aepostoli et euangeliste et sancta Leocadia, sancti Tome aepostoli et sancta Eulalia et sancti Ioannis Babtiste, quorum reliquie humate existunt in ribulo que uocitant Berbecario.

\footnotetext{
${ }^{3}$ Licet primordia bonorum operum, que Deo inspirante in mente gignitur iustitie operibus deputetur tamen ea que maiori cumulo et potiori crescunt in uoto ampliori remuneratione expectatur in premio digne iam sue spei uota in domo celica mansionum multarum conlocat qui domus Sancta Eclesia restaurat uel in melius construere procurat,
}

$$
\text { MODÚBAR (944) }
$$

SILOS (954)

${ }^{1}$ In nomine Ihesu Christe et
indiuidue Trinitatis.

${ }^{2}$ Domnis sanctis inuictissimis ac triumfatoribus martirum, glorioso, uenerando nobisque post Deum fortissimo patrono sancto ac beatissimo Martynum confessori, quorum reliquie condite requiescunt, et in corum honore baselica fundata est in suburbio quod dicunt Agusini, nobisque indignis Didaco Gudesteuz et Assuri Uermudiz et Fredinando Gudesteuz cum uxoribus et filiis nostris et domna Flamula cum filios suos.

\footnotetext{
${ }^{3}$ Licet primordia bonorum operum que, inspirante Deo, in mente gygnitur, iustitie operibus deputetur, tamen ea que mayori cumulo et portiori crescunt, ampliori remuneratione expectatur in premio. Digne igitur iam suo spei uota in domo celica mansionum multarum conlocata, qui domos ęcclesię restaurat uel in melius construere prouocat.
} ${ }^{1}$ In nomine sancte et indivi-
due Trinitatis.

${ }^{2}$ Dompnis sanctis invictissimis ac triumphatoribus martiribus gloriosis atque venerandis nobisque post Deum fortissimis patronis Sanctorum Sebastiani et Sanctorum apostolorum Petri et Pauli et Sancti Emiliani fidelissimi testis Christi, quorum reliquie condite requiescunt, et in quorum honore baselica fundata est in suburbio que vocitant Tablatello super crepidinem fluminis quem dicunt Ura, nobisque indignis Fredenando Gundisalviz et uxor mea Sancia.

\footnotetext{
${ }^{3}$ Licet primordia bonorum operum, que inspirante Deo in mente gignitur, iusticie operibus deputetur, tamen ea que maiori cumulo et pociori crescunt, ampliori remuneratione espectetur in premio. Digne igitur iam sue spei vota in domo celica mansionum multarum colocat, qui domum sancte ecclesie restaurat vel in melius construere provocat.
} 
${ }^{4}$ Nos igitur piacolorum nostrorum honoris pregrabatione cupientes expiari flagitia, et peccatorum nostrorum molem orationum uestrorum desiderantes adiutorium subleuare, parua pro magnis offerimus munuscula; proinde nulliusque idem in hoc seculo omnium uos indigere censum scimus, quia iam per sanctificationem Dominus noster in suo uos regno proprio ditatos munere cumulauit.
${ }^{4}$ Nos igitur Fredenando et Sancia, piacolorum nostrorum honeris pro gravatione cupientes expiare flagicia et peccatorum nostrorum mole, propterea orationes vestras desiderantes adiutorium sublevare, inde parva pro magnis offerimus hunuscula (sic).

Nullius quidem in hoc seculo hominum vos indigeret censum scimus, quia iam pro sanctificatione Dominus noster in suo vos regno proprio ditatus munere cumulavit.

${ }^{5}$ Ideo pro luminaria ecclesie vestre atque stipendia earum vel pauperum, aut qui in altaria beatitudinis vestre et reliquias iam nominati deservire cotidianis diebus videntur monachorum omnium ibidem degencium cunctorumque obediencium, id offerimus sacrosancto altario vestro ad integro, sicut a nobis dignoscitur nunc usque fuisse possesum.

${ }^{6}$ In primis ipsum locum,
in quo hęc eadem ęcclesia
sita est, cum omnibus adia-
centiis uel prestationibus
suis, domum, atrium, terras,
uineas, ortos, molinos, pratos,
padules, cum suis antiquis
productilibus aquis,

${ }^{6}$ In primis, fundamentum ipsius locum, in quo hec eadem ecclesia sita est vel monasterio fundatus, cum omnibus adiacenciis vel prestacionibus suis, domus, atriis, ortis, molinis, pratis, padulibus (sic) cum suis antiquis productilibus aquis

${ }^{7}$ quorum termini hec sunt:

\footnotetext{
${ }^{8}$ de parte orientis Penna Ruvia et Pozo Antiquo semper manante et fosce angusta unde venit aqua de Caraço, ex alia parte Penna Socavata, et exiet ad fosce de Penna Cova;
} 
${ }^{9}$ et de parte occidentis... $\quad{ }^{9}$ et de alia pars...

${ }^{10}$ et in tercia pars...

${ }^{11}$ et in quarta parte...

${ }^{12}$ Et hec omnia determinata que continetur ad parte ęcclesię uestrę cuncta ad integro deliminata iure perenni ęcclesię concedimus.
${ }^{9}$ de parte occidentis, ubi stat crux in Penna ante altare Sancti lacobi et discurrit de inde via ad Sancta Maria, et exiet usque ad summo monte;

${ }^{10}$ et de tercia parte, via que discurrit de ipsa crux iam dicta et vadit pro medio campo inter ambas villas de Silos per altare Sancti Iusti, et exiet usque ad summo monte.

\section{${ }^{12}$ Istos terminos iam dictos cum suis productilibus aquis vel ligna seu pomiferus do- navimus, ut eum ampliora hedificetis, omnia determinata, que continetur a parte eccle- sie vestre, cuncta ad integro deliminata iure perhenni vestre ecclesie concedimus vel confirmamus.}

\begin{abstract}
${ }^{13}$ Hec obtime manere cen-
semus ut tam eglesie quam ibidem nostram quam ni ad iam supra nominatum suis concedimus curam abere, regere et monasticam uitam, dicti regulam, ibidem exercere, nullumque in aliquo eum salubriter inquietare decer-
nimus set quiete et secure perenniter manere precepimus et ut uires eis ministraberint edificare, plantare, procurar on desinant et in suis stiopus eis fuerit expendere licentiam non denegamus eis abere. manere perrecipimus, et ei ministrauerint desinant, et in suis stipendis hac utilitatibus, prout opus fuerit, expendere licentiam
\end{abstract}

\begin{abstract}
${ }^{13}$ Igitur hec obtime munere censemus votum ecclesie, quam et omne nostrum que ibidem tribuimus concessione ad regulam Sancti Sebastiani et Sancti Petri apostoli et Sancti Emiliani presbiteri facimus donationem; et hunc eundem Placenti abbati cum fratribus suis concedimus regere, tenere et monasticam vitam et secundum docet Sancti Benedicti regulam quietem et secure perenniter ibidem exercere, nullusque in aliquo eum salubriter inquietari decernimus, sed quiete et secure perhenniter manere precepimus, et vires que ei ministraverint hedificare, plantare, procurare non desinant, et in suis stipendiis ac utilitatibus, prout opus eis fuerit, vendere, expendere, licenciam non denegamus eis habere. non denegamus eis abere.
\end{abstract}

\footnotetext{
${ }^{14}$ Et insuper accepimus...
} 
${ }^{15}$ Hec numero...

${ }^{16}$ Tamen monemus ut tam iste supra nominatus abba seu futurus qui post eum in loco eius successerit uotum hoc nostrum qualibet tepida conuersatione audeant dissolbere.

${ }^{17}$ Obtamus etiam et eos qui post felicissimum temporibus nostris successerint subolis regum dauitur per eterni regis imperium ut de nostris oblationibus cunctis quibus Deo placere studuimus nihil aufferre nihil emutilare presumant.

${ }^{18}$ Quisquis uero, quod absit, ad inrumpendum ausu temerario uenire niterit hoc nostrum testamentum tam ego quam etiam filiis uel aliquis ex propinquis nostris uibens suis a fronte ambobus careat lucernis postque picea non euadat baratri penam, set cum impiis et iniquis lugeat perpetim.

\footnotetext{
${ }^{19}$ Idem obsecramus tam abbates quam ceteri qui ibidem aduenerint fratres, ut pro sospitate nostra uel incolomitate regni orare non desinant.
}

${ }^{16}$ Tamen monemus, ut tam yste supra nominatus Sancius, seu que futurus qui post eum in loco eius successerit, uotum hoc nostrum qualiuet tepida conuersatione non audeat dissoluere.

${ }^{17}$ Obtamus ętiam eos, qui post obitum nostrum fuerint, de nostris oblationibus cunctis, quibus Deo placere studimus, nicil auferre, nicil emulare presummat.

\begin{abstract}
16 Tamen monemus ut tam iste supra nominatus abba Placenti, seu futuris qui post eum in loco eius successerint, votum hoc nostrum quemlibet tepida conversatione audeat dissolvere.
\end{abstract}

\footnotetext{
${ }^{18}$ Si quis tamen quod absit ad inrumpendum venerit de partem nostram, tam germanis quam et filiis uel subrinis seu neptis aut propinquis auso

\author{
${ }^{18}$ Quisquis quod absit ad \\ disrumpendum venerit istos \\ terminos quomodo, pargiet \\ auree in cauto.
} a parte comite quinque libre
} temerario uenire niterit, sicut supra diximus ypsum cautum pariet et insuper sit damnatus in conspectu Dei Patris et Sancto Martyno uel omnium sanctorum et in hoc seculo exors ab omni cetu religionis Giezi lepra percutiatur; qui nostre oblationis cartula sacrilega mente enerbare uoluerit repentinus iudicius incurrat damnabilis et corpus eius non recipiat terra set quum Iuda traditore abeat portionem in inferno inferiori. Amen. Et descendat super eum sicut descendit super Datan et Abiron quod terra uibos obsorbuit.

\footnotetext{
${ }^{19}$ Idem obsecramus tam abbates quam et ceteri qui ibidem aduenerint fratres ut pro sospitatem nostram orare non pigeant.
} 


\author{
${ }^{20}$ Factum et confirmatum \\ hunc testamentum era $D$ \\ CCCC LXXVIII'. Regnante \\ domno Ranimiro principi in \\ Leione
}

${ }^{20}$ Facta carta confirmatio-
nis kalendas februarias, era
DCCCC. LXXX. II ${ }^{\mathrm{a}}$, regnante
principe Ranimiro in Legione
et comite Fredinando Gundis-
salbiz in Castella.

${ }^{21}$ Ego Didaco Gudistioz et Assur Uermudiz et Fredinando Gudistioz et domna Flamula, qui hanc cartula uoluimus fieri et legendo cognouimus, et sygnum manus nostras expressimus (signos) et testibus ad rouorandum tradimus...

\begin{abstract}
${ }^{20}$ Factum et confirmatum hunc testamentum scriptionis vel confirmationis, notum die sabbato, III nonas iunias, era DCCCCLVII, regnante Domino nostro Ihesu Christo in celis et princeps terre huius rex Ordonio in Legione, comite vero Fredenando Gundisalvet in Castella.
\end{abstract}
${ }^{21}$ Ego, Fredenando Gundissal- vet et uxor mea Sancia quod fecimus roboravimus, et sig- num crucis fecimus ++ .

( $1^{a}$ columna): Munio Didace manum meam roboravi et + feci; Sarracine Scemonoz confirmavi et manu mea + feci; Garcie Bençemaloçe confirmans manu mea + feci; Frande Arguisso confirmans manu mea + feci; Garcia Alvarez confirmans manu mea + feci.

( ${ }^{a}$ columna $)$ : Didaco Simplicio, hic testis; Afonsso, hic testis; Munini Alvarez, hic testis; Beilla Rebellez, hic testis; Teillu Marellez, hic testis.

${ }^{22}$ Iohannes titulavit.

Interesa señalar el gran paralelismo existente, sobre todo, en la parte conminatoria, que resulta tan sospechosa para Zabalza, siguiendo a José María Mínguez ${ }^{57}$. A la vista de estos resultados, hay que plantearse de nuevo la cuestión de la autenticidad de tantos diplomas puestos en duda y por cuyos fueros ya había salido en su día Ernesto Pastor. Por supuesto que no estamos afirmando que todas estas cartas dotacionales sean igualmente auténticas y no las haya falsas o interpoladas. Pero, por lo que hace al documento silense, creemos posible afirmar que es auténtico de principio a fin. Para su redacción se utilizó seguramente una formula de dotación que corría por todo el reino de León, desde principios del siglo $\mathrm{X}$ al menos, y lo hizo hasta el reinado de Fernando $\mathrm{I}^{58}$.

57. J.M. MÍNGUEZ FERNÁNDEZ. Colección diplomática del monasterio de Sahagún..., pp. 32-33; M. ZABALZA DUQUE. Colección diplomática de los condes de Castilla..., p. 126.

58. P. BLANCO LOZANO. Colección diplomática de Fernando I (1037-1065), León, 1987 (Hay edición previa en Archivos Leoneses, XL (1986), pp. 7-212), pp. 86-88 (doc. 24). Su editora lo tiene por sospechoso, pero hay que tener en cuenta lo dicho por E. PASTOR DÍAZ DE GARAYO. 
En resumen, creemos que no se puede tachar de falso el documento de Fernán González a Silos por usar de fórmulas idénticas a las utilizadas por los escribas en cartas dotales de otros monasterios, ya que es lícito suponer que en el siglo X circulaba por el reino de León un formulario de dotación, que fue abundantemente usado. Al menos una de esas cartas, la de San Román de Entrepeñas, es auténtica, por haberse conservado el original. Tampoco el error en la data es prueba de falsedad, porque halla satisfactoria explicación en la que en su día ofreciera Fray Justo Pérez de Urbel. Ni lo es la mención de la Regula Benedicti porque, auténtica en muchos casos desde los inicios del siglo X, no hay razón para dudar de su originalidad en este y otros muchos diplomas ${ }^{59}$. Por otra parte, la extensión del coto señalado al monasterio es tan reducida que parece tuvo que ser así en origen; una falsificación posterior habría sin duda amañado los términos del coto para ajustarlos al momento del amaño. Y, finalmente, desde el punto de vista lingüístico, tampoco hay en el diploma ningún término sospechoso para la época en que se dice escrito.

Por todo ello, creemos que este diploma merece entero crédito, como dirían nuestros antepasados, como seguramente otras muchas cartas de dotación de los siglos X y XI que algunos historiadores han tachado de falsas o interpoladas.

\section{BIBLIOGRAFÍA}

BANGO TORVISO, I. "Reformas monásticas y litúrgicas en relación con los edificios románicos de Santo Domingo de Silos", GARCÍA DE CORTÁZAR, J.A. TEJA CASUSO, R. (Coord.) Los grandes monasterios benedictinos hispanos de época románica (1050-1200), Aguilar de Campoo, 2007, pp. 141165.

DE BERGANZA, F. Antigüedades de España, 2 vols. Madrid, 1719-1721.

BLANCO LOZANO, P. Colección diplomática de Fernando I (1037-1065), León, 1987 (Hay edición previa en Archivos Leoneses, XL (1986), pp. 7-212). DE CASTRO, J. El glorioso thaumaturgo español, redemptor de cautivos, Santo Domingo de Sylos, Madrid, 1688.

DOMÍNGUEZ SÁNCHEZ, S. "En torno a las puntualizaciones sobre la datación de documentos medievales de la catedral de Astorga", Estudios Humanísticos. Historia, 4 (2005), pp. 297-302.

\footnotetext{
"Los testimonios escritos...", pp. 373-374. Otro documento muy similar, sobre el que no recae ninguna sospecha, P. BLANCO LOZANO. Colección diplomática de Fernando I..., pp. 134-136 (doc. 46).

59. Si la mención de la Regula Benedicti estaba en el formulario que suponemos está detrás de estos documentos, aunque no suponga necesariamente su adopción como norma de vida de todos estos monasterios, sí que supondría un indicio de una fuerte presión cultural o política a favor de su implantación en los monasterios hispanos, al menos en la mente de quien lo compuso. Debo esta observación a mi buen amigo, el Dr. Anthony John Lappin (Senior Lecturer in Spanish, University of Manchester President, Society for the Study of Medieval Languages and Literature), siempre dispuesto a revisar mis artículos y enriquecerlos con sus atinados comentarios.
} 
ESCALONA, J., VELÁZQUEZ, I., JUÁREZ, P. “Identification of the sole extant original charter issued by Fernán González, Count of Castile (932-970)", Journal of Medieval Iberian Studies, 4/2 (2012), pp. 259-288. http://dx.doi.org/10. 1080/17546559.2012.732441

FÉROTIN, M. Histoire de l'abbaye de Silos, París, 1897.

- Recueil des chartes de l'abbaye de Silos, París, 1897.

DE FERRERAS, J. Synopsis historica chronológica de España. Parte décima sexta, Madrid, 1775.

FLÓREZ, E. España sagrada, vols. XXVI-XXVII, Madrid, 1771-1772.

DU FRESNE, C. Glossarium mediae et infimae latinitatis, 10 vols., Niort, 1883-1887.

GARCÍA DE CORTÁZAR, J.A. "Monasterios románicos de Castilla y conservación de la memoria histórica", Monasterios románicos y producción artística, Aguilar de Campoo, 2003, pp. 9-33.

GARCÍA LUjÁN, J.A. Códice Diplomático procesal del Monasterio de Santo Domingo de Silos (1346): estudio codicológico, paleográfico, diplomático y edición, Córdoba, 1996.

GARCÍA RODRÍGUEZ, C. El culto de los santos en la España romana y visigoda, Madrid, 1966.

DE GARIBAY, E. Compendio historial de las chrónicas y universal historia de todos los reynos de España, vol. I, Barcelona, 1628.

GIL, J. Miscellanea Wisigothica, Sevilla, 1972.

GÓMEZ, A. El Moysen segundo, nuevo redentor de España, N. P. Santo Domingo Manso, monge benito (aclamado hasta ahora Santo Domingo de Silos), Madrid, 1653.

LAFFÓN ÁLVAREZ, L. “Arenga hispana: una aproximación a los preámbulos documentales de la Edad Media", Historia. Instituciones. Documentos, 16 (1989), pp. 133-232.

DE LERA MAÍLLO, J.C. "Noticia descriptiva del cartulario gótico del Monasterio de Silos", Silos. Un milenio. Actas del Congreso Internacional sobre la Abadia de Santo Domingo de Silos (II. Historia), Silos, 2003 (Stvdia Silensia XXVI), pp. 521-540.

LINAGE CONDE, A. Los orígenes del monacato benedictino en la península ibérica, 3 vols., León, 1973.

MARTÍNEZ DÍEZ, G. Colección documental del monasterio de San Pedro de Cardeña, Burgos, 1998.

-. El condado de Castilla (711-1038). La historia frente a la leyenda, 2 vols., Valladolid, 2005.

MÍNGUEZ FERNÁNDEZ, J.M. Colección diplomática del monasterio de Sahagún (siglos IX y X), León, 1976.

DE MORET, J. Investigaciones históricas de las antigüedades del reyno de Navarra, Pamplona, 1665.

NIERMEYER, J.F., VAN DE KIEFT, C. Mediae Latinitatis Lexicon Minus, 2 vols., Leiden, 2002. 
PASTOR DÍAZ DE GARAYO, E. "Los testimonios escritos del sector meridional de Castilla (siglos X-XI). Ensayo de crítica documental”, Historia. Instituciones. Documentos, 24 (1997), pp. 355-380.

PÉREZ DE URBEL, J. Historia del condado de Castilla, 3 vols., Madrid, 1945.

LA RIPA, D. Defensa histórica por la antigüedad del reino de Sobrarbe, Zaragoza, 1675.

RUIZ ASENCIO, J.M., RUIZ ALBI, I., HERRERO JIMÉNEZ, M. Colección documental del monasterio de San Román de Entrepeñas (940-1608), León, 2000.

—. Los becerros gótico y galicano de Valpuesta, 2 vols., [Burgos], 2010.

SÁENZ DE AGUIRRE, J. Collectio maxima conciliorum omnium Hispaniae et novi orbis, vol. III, Roma, 1694.

SÁEZ, E., SÁEZ, C. Colección documental del archivo de la catedral de León (775-1230). II (953-985), León, 1990.

SALAZAR Y CASTRO, L. Historia genealógica de la casa de Lara, vol. I, Madrid, 1696.

SECO, M. (coord.) Léxico hispánico primitivo (siglos VIII al XII). Versión primera del Glosario del primitivo léxico iberrománico, Madrid, 2008.

SENRA, J.L. "Mutatis mutandis: creaciones apócrifas en el monasterio de San Pedro de Arlanza (Burgos)", Cahiers de linguistique hispanique médiévale, 29 (2006), pp. 23-43.

SERRANO, L. Cartulario de San Pedro de Arlanza, Madrid, 1925.

-. El obispado de Burgos y Castilla primitiva desde el siglo V al XIII, 3 vols., Madrid, 1935-1936.

VIVANCOS, M.C. Documentación del monasterio de Santo Domingo de Silos (954-1254), Burgos, 1988 (Fuentes medievales castellano-leonesas 50).

-. Documentación del monasterio de Santo Domingo de Silos (1255-1300), Silos, 1995 (Stvdia Silensia XVIII).

—. "El Monasterio de Silos y su scriptorium; Catálogo. El scriptorium silense y los orígenes de la lengua castellana", J.C. ELORZA. (coord.) El scriptorium silense y los orígenes de la lengua castellana, Valladolid, 1995, pp. X-XL; $1-33$.

—. Glosas y notas marginales de los manuscritos visigóticos del monasterio de Santo Domingo de Silos, Silos, 1996 (Stvdia Silensia XIX).

—. "Circulación de manuscritos en la Edad Media: el caso de San Millán y Silos", M. BIELAWSKI, D. HOMBERGEN. (coords.) Il monachesimo tra eredità e aperture, Roma, 2004 (Studia Anselmiana 140), pp. 785-802.

—. "Santo Domingo de Silos, Monasterio de", Gran Enciclopedia de España, vol. XX, Barcelona, 2004, pp. 9600-9602.

-. Catálogo del archivo del monasterio de Santo Domingo de Silos, Silos, 2006 (Stvdia Silensia XXIX).

DE YEPES, A. Corónica general de la Orden de San Benito, vol. IV, Valladolid, 1613. 
ZABALZA DUQUE, M. "Escrituras de fundación de los monasterios de Arlanza y Silos. Problemas sobre su autenticidad", Boletín de la Institución Fernán González, LXXIV (1995), pp. 333-361.

- Colección diplomática de los condes de Castilla: edición y comentario de los documentos de los condes Fernán González, García Fernández, Sancho García y García Sánchez, Valladolid, 1998.

ZEUMER, K. Formulae merowingici et karolini aevi. Accedvnt ordines ivdiciorvm Dei, Hannover, 1886 (MGH, Legvm Sectio V, Formvlæ).

Fecha de recepción del artículo: enero 2013

Fecha de aceptación y versión final: septiembre 2013 